\title{
Simplified mashing efficiency. Novel method for optimization of food industry wort production with the use of adjuncts
}

\author{
Łukasz P. Szwed, Ewa Tomaszewska-Ciosk*, Józef Błażewicz \\ University of Environmental and Life Sciences in Wroclaw, Department of Food Storage and Technology, \\ ul. Chetmońskiego 37/41, 51-630 Wroclaw, Poland \\ "Corresponding author: e-mail: ewatc@wnoz.up.wroc.pl
}

\begin{abstract}
Malt extracts and malt concentrates have a broad range of application in food industry. Those products are obtained by methods similar to brewing worts. The possible reduction of cost can be achieved by application of malt substitutes likewise in brewing industry. As the malt concentrates for food industry do not have to fulfill strict norms for beer production it is possible to produce much cheaper products. It was proved that by means of mathematic optimization it is possible to determine the optimal share of unmalted material for cheap yet effective production of wort.
\end{abstract}

Keywords: mathematic optimization, mashing efficiency, wort production, malt concentrates for food industry.

\section{INTRODUCTION}

Malt extracts and malt concentrates are water extracts of malt or mixture of malt and unmalted material. They are obtained by mashing process and preserved by evaporative concentration and/or spray drying ${ }^{1}$. In food industry they are used as half-products at home brewing (as a part of „brew-kits”), coloring and taste agents, components altering the processing properties of dough or carbohydrate diet supplements ${ }^{2,3,4}$. The economic aspects of production demand that in industrial conditions the expensive raw materials are replaced by cheaper substitutes. In brewing malt is industry the most expensive raw material, which with acceptable loss of quality, may be substituted by the other source of extract without a significant loss of quality ${ }^{3,5,6,7,8}$. The cost reduction of raw material is linked with a choice of proper malt substitute. It should be characterized by easy processing and abundance of extract substances. Consequently, the application of preprocessed carbohydrate syrups or cereals grains seems very reasonable. The latter ones are usually brewing barley grain, , low protein wheat, and maize. Although scientific research present trials to use other, more exotic cereals or even potato $\operatorname{starch}^{6,9,10,11,12}$. In Poland the most popular unmalted adjunct is a product obtained from maize deprived of embryo (maize grist and fine maize grist both domestic and imported $)^{5,13}$, or products of enzymatic hydrolysis of wheat starch (in the form of a concentrated syrup). Other cereals hydrolysates (obtained by enzymatic or acidic hydrolysation of whole cereal grain) are not used in Polish brewing industry.

The compositions of worts obtained with unmalted material differ from brewing wort. Those are quantity and "quality" of hydrolysis products: peptides, carbohydrates, non-starch polysaccharides, tannins and other components. The broad materials of subject ${ }^{7,8,9,12,14,15,16,17}$ focus, on decreased levels of yeast assimilable aminoacids, foam stabilizing peptides, and possible increase of non-starch polysaccharides and tannins (especially when unmalted barley is used). Although the wort obtained with high share of unmalted material can be disqualified from brewing it does not apply to other branches of food industry. The unnormative worts can be successfully used as coloring agents and carbohydrate additives to broad range of food products.

In the course of production the substances not extracted from malt are treated as a waste, called brewers spent grain. The amount of brewers spent grain is determined by charge of malt used, as well as mashing efficiency. The mathematic data processing allows not only to control the technological process, but also to forecast the result of mashing. In the presented research the simplified mashing efficiencies were calculated and the trend lines were set for dependencies of unmalted material share and type of malt. The method allowed to obtain a model from a few trials which can be used for process optimization and to reduce the amount of brewers spent grain created.

\section{MATERIAL AND METHODS}

The materials of the experiment were two types of malt: which were Pilsner type malt from Strzegom malthouse (Diastatic Power 250 WK, Colour 3.2-4.5 EBC, Extractivity $80 \%$, Protein content $9-11.5 \%$ ) - as an example of highly diastatic malt, and crystal light malt „Carahell” produced by Weyermann (Diastatic Power $<50 \mathrm{WK}$, Colour 20-30 EBC, Extractivity 74\%, Protein $10.6-12 \%)$ - as an example of malt with increased "taste" perception, and decreased diastatic power. As an adjunct 5 types of unmalted materials were used: maize grist (granulation $750-1250 \mu \mathrm{m}$ ) from two independent suppliers (marked in experiment as: A (starch content of $86.15 \mathrm{~g} / 100 \mathrm{~g}$ ) and B (starch content of $85.59 \mathrm{~g} / 100 \mathrm{~g})$ ), fine maize grist (granulation $250-750 \mu \mathrm{m}$ ) from before mentioned suppliers (similarly marked: A (starch content of $87.07 \mathrm{~g} / 100 \mathrm{~g}$ ) and B (starch content of 85.59 $\mathrm{g} / 100 \mathrm{~g})$ ) and dehusked brewing barley grain obtained from Sierpc malthouse (starch content of $69.72 \mathrm{~g} / 100 \mathrm{~g}$ ). To supplement the decreased amounts of malt enzymes the enzymatic preparations from Novozymes were used - Termamyl 120L Type L and Ceremix Plus which are recommended for mashing with high share of unmalted material.

The presented material was processed in laboratory scale in Automatic Mashing apparatus LB-12 Electronic from Lochner LaborTech according to the procedure below. All worts were obtained in at least 6 replicates. 
The weighted portion of unmalted material dry mass was subject of pretreatment, which was gelatinization of raw material with $200 \mathrm{ml}$ of distilled water in presence of Termamyl $120 \mathrm{~L}$ enzymatic preparation (in maximal dose suggested by producer $-0.05 \mathrm{~g}$ of preparation/sample). The gelatinization phase was aimed at physical and enzymatic pretreatment of unmalted material's starch. The process of gelatinization increases the viscosity of solution, but $\alpha$-amylase activity of preparation causes partial hydrolysis of starch, which liquefies the mixture. The process was conducted in $75^{\circ} \mathrm{C}$ for 45 minutes with intense stirring (200 rpm). After cooling to $45^{\circ} \mathrm{C}$, the variant proper share of malt was added, as well as Ceremix Plus enzymatic preparation (in maximal dose suggested by producer $-0.05 \mathrm{~g}$ of preparation/sample). The process of mashing was conducted according to Analytica EBC 4.5.1. with default preprogrammed settings.

Overall 34 variants of laboratory worts were produced in which 40,60 or $80 \%$ of charge was substituted by one of the unmalted materials. The reference samples were made from malt only and malt supplemented by enzymatic preparations.

The obtained worts were subject of final volume measurement and determination of extract content according to EBC 4.5.1. method. The final volume was measured in glass volumetric cylinder with $5 \mathrm{ml}$ accuracy. The extract content was measured with automatic densitometer Densito 30PX from Metler Toledo. The obtained results were used in the following formulae: $u W=B \cdot 10 \cdot\left(V_{k} / V_{\max }\right)$

$\mathrm{uW}$ - simplified efficiency of mashing,

$\mathrm{B}$ - extract content of wort [\% w/w],

$\mathrm{V}_{\mathrm{k}}$ - final volume of wort,

$\mathrm{V}_{\text {max }}$ - maximal volume of wort - for congress method set to $400 \mathrm{ml}$.

The results were subjects of statistical analysis with one-way ANOVA. The homogenous groups were determined by Duncan's test with significance level $\alpha=0.05$. The analysis were performed with STATISTICA 9.0 from Statsoft.

\section{RESULTS AND DISCUSSION}

The final volume of wort not the extract content alone can be used as a measure of the wort quality. It is possible to obtain a large volume of wort but deficient in extract, or a smaller portion of wort with high extract content. In order to compare the efficiency of wort obtainment the parameter, called simplified mashing efficiency, was calculated. The value of $66.65 \%$ was treated as normal (marked on diagrams as dotted line), which was justified by literature data (minimal extract of $8.6^{\circ} \mathrm{P}$ and final volume of $310 \mathrm{ml})^{17}$. Additionally the value of $75.7 \%$ (the dashed line), the average for all-malt control variants, was set as a standard for high efficient process.

All of the presented figures contain the least significant value (LSD) which is the deviation from average value that allows to claim significant change in value. Additionally the homogenous groups were marked with letters.

Figures describing the influence of increasing share of unmalted material on simplified mashing efficiency also contain the second degree polynomial equation describing the change of simplified mashing efficiency, with their coefficient of determination $\left(\mathrm{R}^{2}\right)$. With the increase of unmalted material share the simplified efficiency of mashing decreases but the share which the effect is observed is dependent for the type of unmalted material. For maize grist A (Fig. 1), maize grist B (Fig. 2), fine maize grist B (Fig. 4) significant loss of mashing efficiency, when compared to all-malt with enzymatic preparation control, was observed with $40 \%$ share of unmalted material. On the opposite, samples obtained from fine maize grist A (40\%) (Fig. 3) were characterized with an increased mashing efficiency, even when compared to all-malt with enzymatic preparation,

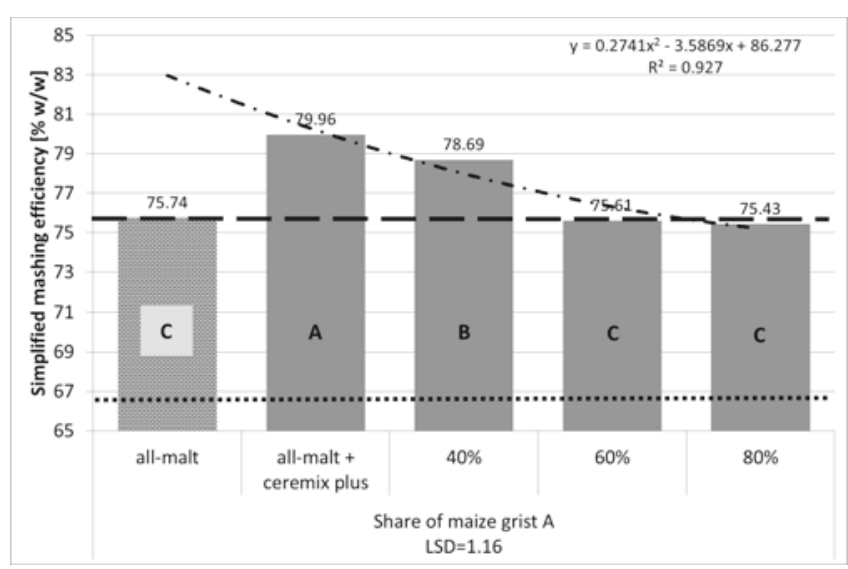

Figure 1. Dependency of simplified mashing efficiency from share of maize grist A. The letters mark homogenous groups

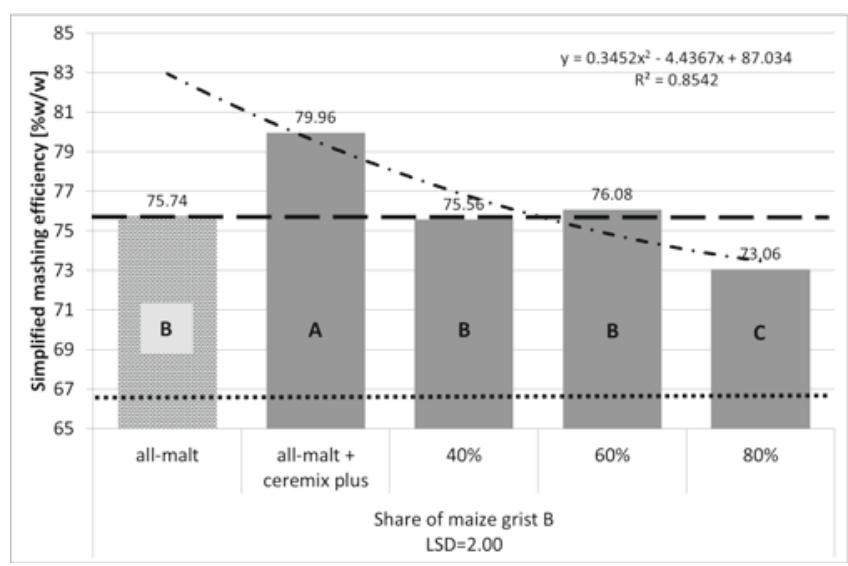

Figure 2. Dependency of simplified mashing efficiency from share of maize grist B. The letters mark homogenous groups

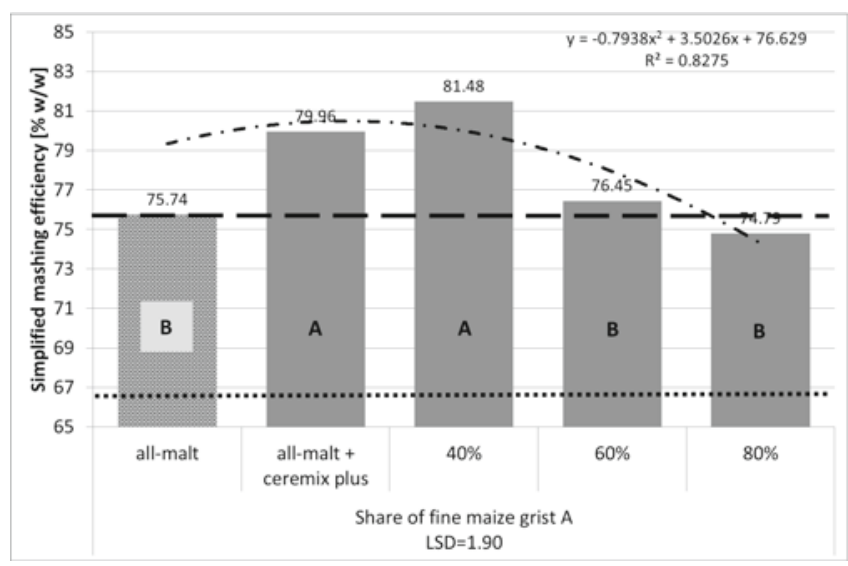

Figure 3. Dependency of simplified mashing efficiency from share of fine maize grist A. The letters mark homogenous groups 
although statistical analysis revealed it was insignificant. The obtained average result of $81.48 \%$ mashing efficiency was the highest observed. The variants obtained with $40 \%$ share of unmalted brewing barley (Fig. 5) were characterized with lesser values $(78.25 \%)$ of simplified mashing efficiency, but the change was calculated as statistically not significant. The $60 \%$ share of unmalted material in the charge effected in further loss of mashing efficiency, to the levels similar to all-malt control samples, despite of the type of unmalted material used (Figs. 1-5). The $80 \%$ share of unmalted material, despite the fact that type of material used, were characterized with the

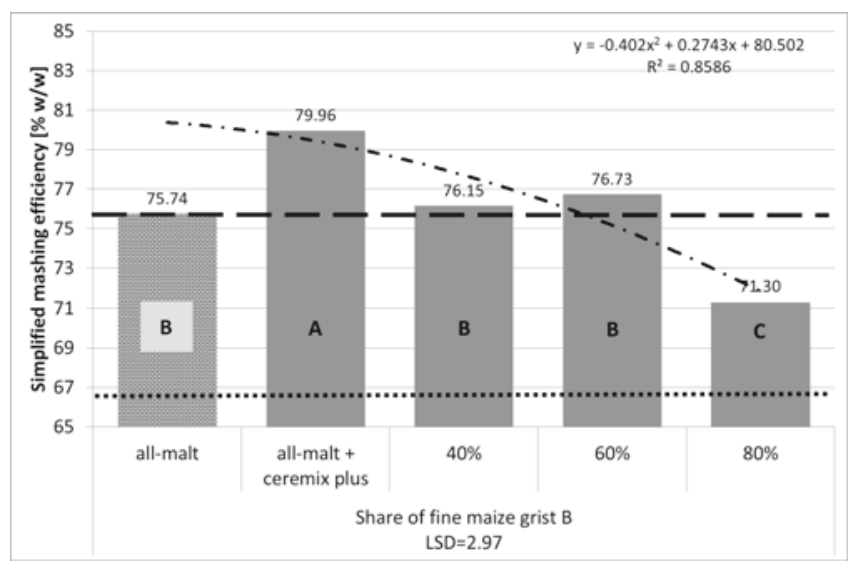

Figure 4. Dependency of simplified mashing efficiency from share of fine maize grist B. The letters mark homogenous groups

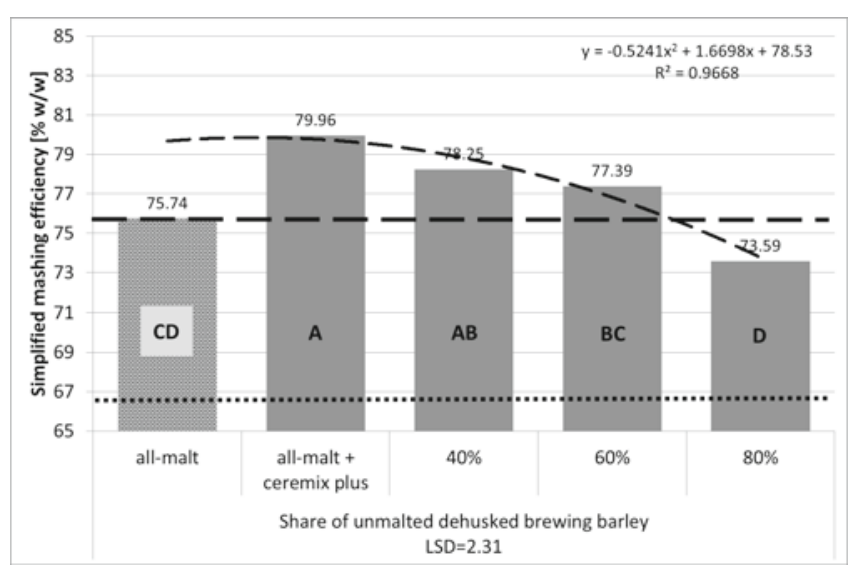

Figure 5. Dependency of simplified mashing efficiency from share of unmalted dehusked brewing barley. The letters mark homogenous groups

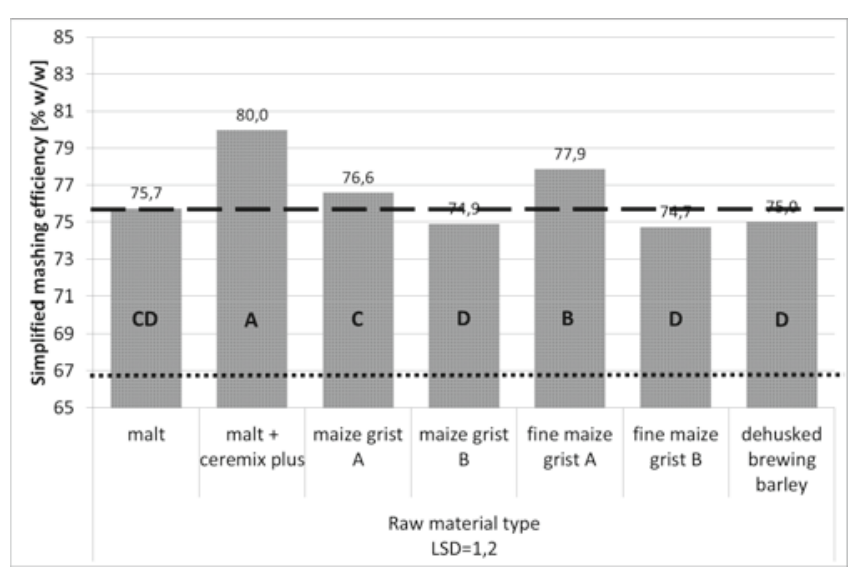

Figure 6. Dependency of simplified mashing efficiency from type of unmalted raw material. The letters mark homogenous groups. lowest simplified mashing efficiency. All of the values were lesser than all-malt control group, but only in case of maize grist B (Fig. 2), fine maize grist B (Fig. 4) and unmalted brewing barley the loss of mashing efficiency was statistically significant.

Those results can be explained by the composition of raw materials. Increasing substitution of malt with unmalted material reduces the amount of enzymes pool required for lysis and in effect transformation to soluble state of sugars and peptides ${ }^{\mathbf{1 0}, \mathbf{1 2}, \mathbf{1 8}}$. As initially addition of enzymatic preparation counters the negative effect, which can be observed by values greater or similar to all-malt control samples, the effect slowly degrades with share of adjunct excessing the $40 \%$.

The type of unmalted raw material significantly affects the simplified mashing efficiency (Fig. 6). The greatest values were noted for worts obtained from all-malt charge with addition of Ceremix Plus enzymatic preparation (average of $80.0 \%$ ). The next statistically homogenous groups were worts obtained with application of fine maize grist A (average of $77.9 \%$ ), as well as maize grist A (average of 76.6\%). The worts obtained with application of maize grist A showed similarities with worts from malts only (average of $75.7 \%$ ). The control variants from malt also showed similarities with the last homogenous group, which contained variants achieving the set normal standard, but they did not exceed the high standard, the group consisted of variants of worts obtained with application of maize grist $\mathrm{B}$, fine maize grist B and dehusked brewing barley grain (respectively averages of 74.9, 74.7 and $75.0 \%$ ).

The influence of the type of raw material is linked with its composition. The maize is mostly source of carbohydrates which qualifies it is common used as an adjunct in brewing industry $5,10,12,13,17$. The maize grain deprived of embryo is easily processed and generally stable year to year in its composition. Although observed differences between maize from two suppliers suggest that the material processing requires further study. Although the barley starch is similar to malt starch ${ }^{\mathbf{1}, 17}, \mathbf{1 9}$, it should be noted that brewing barley grain was characterized by lower starch content, and increased content of ballast substances (hampering filtration) than the maize grists. The obtained results of simplified mashing efficiency were lower than control samples. As was observed the lack of husk caused hampered filtration, and decreased final volume of obtained wort.

Although the presented, in the research, trend lines for simplified mashing efficiency had their determination coefficients $\left(\mathrm{r}^{2}\right)$ near to unity $(0.82-0.96-$ which is commonly described as good to very good), their application is restricted to the mashing method used. Although the prognosis model is restricted to specific infrastructure of brewhouse, applied type of unmalted raw material, malt type etc. it should be noted that conduction of a few tests allows to create model for further optimization of process. Proper choice of parameters and data gathering may translate to more general model in the future. The general model would be characterized by lower determination coefficient and would be specific to infrastructure of brewhouse, but would allow to determine proper composition of charge for specific type of unmalted raw material and malt. Although the general 
tendencies were determined with high accuracy for variants with maize milling products, it was noted that the functional models should be broadened with additional measures of different shares of unmalted material. In the opposite every industry brewhouse could research their own, material specific model. It should be noted that year to year measurements would have to be handled, because of varying vegetation seasons affecting diastatic power of malts, and affecting composition of adjuncts.

\section{CONCLUSIONS}

The application of enzymatic preparations increases the mashing efficiency.

Supplementation of malt enzymes with enzymatic preparation allows to replace up to $60 \%$ of malt share with unmalted material without significant loss of simplified mashing efficiency.

The mathematical obtained models are characterized by high values of determination coefficients, which suggests practical implementation of the method as plausible.

\section{LITERATURE CITED}

1. Błażewicz, J. (2004). Properties of worts and malt concentrates obtained with addition of potato starch, triticale grain or barley as an malt substitute. Zesz. Nauk. AR we Wrocławiu, 491, Rozprawy CCXVII, 1-94.

2. Błażewicz, J. \& Borek, M. (1999). Aplication of bakery type malt extracts in food industry. Cukiernictwo, 2, 15.

3. Baik, B.K. \& Ullrich, S.E. (2008). Barley for food: Characteristics, improvement, and renewed interest; J. Cer. Sci., 48, 233-242. DOI: 10.1016/j.jcs.2008.02.002.

4. Pharmaceutical Society of Great Britain. (1907). British pharmaceutical codex. 401-404.

5. Błażewicz, J. \& Zembold-Guła, A. (2007). Milled corn products in worts production, Pol. J. Food Nutr. Sci., Vol. 57, No. 4(A), pp. 41-44.

6. Agu, R. \& Palmer, G. (1998). A reassessment of sorghum for lager-beer brewing, Bioresource Technol., 66, 253-261. DOI: 10.1016/S0960-8524(98)00047-9.

7. Błażewicz, J., Figiel, A., Stępień, B. \& Peroń, S. (2002). Influence of unmalted grain on the properties of thickened malt worts; Acta Agrophysica 77, 7-14.

8. Lloyd, W. (1986). Centenary review-adjuncts; Journal of the Institute of Brewing, 92, 336-345. DOI: 10.1002/j.20500416.1986.tb04420.x.

9. Taylor, J. \& Boyd, H. (1986). Free alfa-amino nitrogen production in sorghum beer mashing, J. Sci. Food Agric. 37, 1109-1117.

10. Błażewicz, J., Zembold-Guła, A. \& Szwed, Ł. (2009). Worts production with addition of milled corn products; Food Technology Operations - New Vistas; Wydawnictwo UP we Wrocławiu Ed. By Kopeć W., Korzeniowska M., 160-168.

11. Glatthar, J., Heinisch, J. \& Senn, T. (2003). The use of unmalted triticale in brewing and it's effect on wort and beer quality; J. Am. Soc. Brew. Chem., 61, 182-190. DOI: 10.1094/ ASBCJ-61-0182.

12. Shariffa, Y.N., Karim, A.A., Fazilah, A. \& Zaidul, I.S.M., (2009). Enzymatic hydrolysis of granular native and mildly heat-treated tapioca and sweet potato starches at sub-gelatinization temperature; Food Hydrocolloids, 23, 434-440. DOI: 10.1016/j. foodhyd.2008.03.009.

13. Jurek, K., Błażewicz, J. \& Petrów, A. (2004). Properties of beers, obtained with addition products of maize milling, in conditions of simplified technology [in Polish], Żywność-Nauka, Technologia, Jakość 3(40) Supl., 109-118.
14. Charalambous, G. (1981). Nitrogenous constituent of beer, Brewing Science vol no2. edited by Pollock, Academic Press New York, 196-214.

15. Fumi, M., Galli, R. \& Donadini, G. (2006). Brewing process and phenolic compounds in beer. Proceeding Convention 2006 - The Institute of Brewing \& Distilling - Asia Pacific Section - Hobart, Tasmania.

16. Abernathy, D.G., Spedding, G. \& Starcher, B. (2009). Analysis of protein and total usable nitrogen in beer and wine using a microwell ninhydrin assay; J. Inst. Brew. 115(2), 122-127. DOI: 10.1002/j.2050-0416.2009.tb00356.x.

17. Kunze, W. (2010). Technolgy Brewing and Malting; ISBN: 978-3-921690-64-2.

18. Goode, D.L., Wijngaard, H.H. \& Arendt, E.K. (2005). Mashing with Unmalted Barley-Impact of Malted Barley and Commercial Enzyme (Bacillus spp.) Additions; Master Brewers Association of the Americas Technical Quarterly vol. 42, no. 3, 184-198, DOI: 10.1094 / TQ-42-0184

19. O’Rourke, T. (1996). Brewing. In: Industrial Enzymology, $2^{\text {nd }}$ ed., 105-131. T. Godfrey and S. West, Eds. Macmillan, London. 